\title{
Social Entrepreneurship in Theory and Practice-An Introduction
}

\author{
Nicola M. Pless
}

Published online: 21 November 2012

(C) Springer Science+Business Media Dordrecht 2012

The field of social entrepreneurship has grown exponentially in recent years and has become a social, economic and cultural phenomenon. In light of the current economic crisis, the inability of some governments to meet the social needs of their constituencies, a widening gap between rich and poor in many developed countries, and-for many-a less than appealing, scandal-ridden corporate world, the stories of individuals and groups of individuals who want 'to change the world' (Bornstein 2004) are inspiring. The examples of dedicated and visionary entrepreneurs who design solutions for unmet social needs, and whose primary intention is to help others, are a source of hope in markets where traditional forms of capitalism are struggling to rebuild their reputation and legitimacy.

From a research perspective, Dacin et al. (2011) offer a more muted reception for social entrepreneurship. As increasing numbers of researchers venture into the intriguing, interdisciplinary context of social entrepreneurship, 'researchers continue to struggle to delineate boundaries of the field and to arrive at a set of relevant and meaningful research questions' (p. 1203). As a consequence, social entrepreneurship research is still in an embryonic state and a unified definition is missing (Short et al. 2009, p. 161). However, the most scholars agree that a broad definition should be adopted given the cross-sectoral and interdisciplinary nature of the social entrepreneurship field. In an early attempt to bring structure in a nascent field, Mair and Marti (2006, p. 37) define social entrepreneurship 'as a process involving the innovative use and combination of resources to pursue opportunities to catalyse social change and/or address

N. M. Pless ( $\square)$

ESADE Business School, Ramon Llull University,

Sant Cugat, Spain

e-mail: nicola.pless@esade.edu social needs.' Their definition moves beyond the initially dominating stream of research on social entrepreneurs and the personalities, qualities, values and visions of individual change agents (Bornstein 2004). While these often powerful and inspiring stories help to popularise the field and continue to inspire, scholars have lately called for a broader, and at the same time, more focused approach. Short et al. (2009) conducted an in-depth review of the social entrepreneurship field and found only ' 152 relevant articles'. They concluded that to establish a more unified terminology, researchers should embrace key themes in strategic entrepreneurship — such as contingency theory, discovery theory and resource dependency theory. Dacin et al. (2011) suggested five avenues of 'theory building at varying levels of analysis: institutions and social movements, networks, culture, identity and image and cognition' (p. 1211) and emphasised the importance of context and outcomes. In particular, Dacin et al. emphasised the relevance of social processes in the pursuit of social entrepreneurship. They located existing research in four key areas: (1) the characteristics of individual social entrepreneurs; (2) their sphere of operation and the social needs and constituencies targeted; (3) the processes and resources used-it is in this area where core research questions are identified and (4) the mission of the social entrepreneur/ enterprise.

This Special Issue - the first of its kind in the Journal of Business Ethics - seeks to advance the discourse on, and theory building in, social entrepreneurship. With few exceptions (e.g. Koe and Shamuganathan 2010; VanSandt et al. 2009; Murphy and Coombes 2009; Sud et al. 2009) social entrepreneurship has yet to be embraced as a research domain in this journal. By assembling some of the leading scholars in the field, the Special Issue aims to encourage more relevant research and enhance the understanding of social entrepreneurship and its ethical, social 
and contextual implications. The scope of contributions is broad and paradigmatic in nature, touching on all the key areas identified above. Moreover, the papers selected for this Special Issue respond to the suggestion made by Dacin et al. (2011, p. 1211) that a focus on outcomes (positive and negative) and context constitute the most meaningful way of understanding social entrepreneurship, both theoretically and empirically. The papers in this volume investigate how charity and entrepreneurial cultures shape social entrepreneurship; how positive outcomes depend on whether a value creation or a value capture approach is adopted; how different social entrepreneuring models lead to different outcomes and why researchers need to broaden their perspective beyond the individual level to include collective forms of social entrepreneurship. In addition, this issue features two in-depth case studies on social entrepreneurs and their enterprises, and examines how these individual creations' became collaborative efforts.

In the first article 'A Tale of Two Cultures: Charity, Problem-Solving and the Future of Social Entrepreneurship', J. Gregory Dees explains two different (sometimes complementary, sometimes conflicting) value systems, or clusters of cultures, that constitute the domain of social entrepreneurship. Both of these systems, he explains, are rooted in our psychological responses to the needs of others and are reinforced by social norms. One of these systems is the age-old culture of charity in which a selfless action is performed for the benefit of another person out of compassion and the charitable actor is rewarded with personal happiness. The second system encompasses the more contemporary culture of entrepreneurial problem-solving, where skills are judged by the usefulness of results and the excellence of the methods employed in contributing to meaningful lives. Social entrepreneurship, in his view, can be regarded as a recent extension of the analytic problemsolving cluster. He stresses five areas of differences and tension between charity and entrepreneurial problem-solving: (1) spontaneous charity versus reasoning about social return; (2) honouring sacrifice and justifying weak results versus the need for talent and expertise to address challenges;

(3) pure giving versus employing business-like approaches; (4) relieving suffering versus solving the problem and its cause and (5) caring for people versus empowering people. J. Gregory Dees argues that the most social entrepreneurs rely to some degree, at least in the early phase of activities, on resources that are given out of a charitable impulse. But he goes further in arguing that the success of social entrepreneurship depends on aligning these two cultures (and their inherent values) so that the personal satisfaction of giving can help further the contribution of smart problem-solving for the good of society. In the final part of the article, J. Gregory Dees presents a strategy for a new, blended culture in which he emphasises the importance of: learning empathy and problem-solving skills; making performance information more visible and accessible; making 'smart giving' fashionable; engaging supporters in problem-solving and improving the affective positioning of problem solvers (i.e. making problem solvers appealing to those factors that drive charitable behaviour).

In the second article, entitled 'A Positive Theory of Social Entrepreneurship', Filipe M. Santos develops a theory that advances scholarly research in social entrepreneurship by explaining its distinctive role in the economic system, and pointing to the specifics of the social entrepreneurship approach as opposed to traditional forms of entrepreneurship. The author argues for a definition that goes beyond entrepreneurship with a 'social mission' or a 'social purpose' (as has often been the case in mainstream social entrepreneurship approaches), and beyond comparisons of economic versus social value (and thus prompting the need to classify what is social and what is not). He adopts a descriptive view and stresses the need to decide if a company's focus and intended goal is predominately value creation (i.e. creating a strong and important impact for society in general) or value capture (i.e. appropriating a substantial portion of the value created with the aim of making a profit). According to Santos neither profit-oriented companies nor governments (due to a lack of resources) will systematically engage in areas and activities perceived as having a high potential for value creation but little potential for value capture (such as eradicating diseases or malnutrition in developing countries). These situations of simultaneous market and government failure remain the domain of social entrepreneurs. The author defines social entrepreneurship as the pursuit of sustainable solutions to neglected problems with positive externalities. He discusses when it is likely that problems with externalities will be neglected (i.e. when the externalities are localised-meaning they benefit just a segment of the population, e.g. racial minorities or elderly people). He also describes the central goal and approach of social entrepreneurs, which is (1) to seek sustainable solutions rather than sustainable advantages and (2) to develop solutions built on the logic of empowerment rather than the logic of control. The author uses economic and institutional arguments to advance theories on social entrepreneurship.

The third contribution to this Special Issue, 'Organizing for Society: A Typology of Social Entrepreneurship Models' by Johanna Mair, Julie Battilana and Julian Cardenas, does not rely on preconceived definitions and conceptualisations of social entrepreneurship, but derives a typology of social entrepreneuring models from descriptions provided by social entrepreneurs themselves. A global sample of 200 social entrepreneurial organisations that intend achieving social change with the support of two organisations (Schwab Foundation and Ashoka) was 
content- and cluster-analysed by the authors and the commonalities were identified to derive a social entrepreneuring model. The components analysed were (1) the issue domain in which a social entrepreneuring company wants to make a difference; (2) the target constituencies involved in the process; (3) the activities in which a company engages and (4) the justification of the proposed solution or action (e.g. the principles or 'orders of worth' in terms of inspiration or markets). The results lead to four social entrepreneuring models that mobilise different types of capital: (a) political capital; (b) human capital; (c) economic capital and (d) social capital. The findings also reveal an underlying logic of justification that may explain different ways of organising across organisations. This study's contribution embraces the heterogeneity that exists in social entrepreneurship as a practice. It also encourages further research on different organisational approaches adopted by social entrepreneurs and acknowledges the need for research at different levels (e.g. at the organisational and field level).

In 'Collective Social Entrepreneurship: Collaboratively Shaping Social Good', A. Wren Montgomery, Peter A. Dacin and M. Tina Dacin argue that past research has overemphasising 'heroic' and individual views of social entrepreneurship and neglected an important area that they label 'collective social entrepreneurship'. By its collaborative nature, collective social entrepreneurship contributes to substantive and scalable social change. The authors define collective social entrepreneurship as collaboration amongst similar and diverse actors for the purpose of applying business principles to solve social problems. This collective action enables acquiring and deploying resources from multiple actors through different activities and strategies that mobilise supporters, share ideas and knowledge, represent diverse viewpoints, build credibility, save costs and drive change. A conceptual framework of collective social entrepreneurial work is presented using illustrative case studies. The framework shows that collective social entrepreneurs work at multiple levels: pooling (sharing similar resources) and trading (complementary) resources within and between sectors (government, for profit and notfor profit). The authors acknowledge that much collective social entrepreneurial work involves pooling and trading simultaneously. Referring to the discussion of the management of resource flows, the authors enlist three interrelated sets of activities that facilitate and enhance the work of collective social entrepreneurs: (1) framing (i.e. constructing action-oriented sets of beliefs that mobilise collective action); (2) convening (i.e. convincing individuals, groups or networks to collaborate and jointly address complex issues) and (3) multivocality (i.e. combining multiple voices and multiple lenses to speak to a variety of audiences). The authors provide suggestions for further research and conclude their contribution by highlighting the important role that collective social entrepreneurship plays across sectors in creating markets, new institutions, dismantling outdated institutional arrangements and addressing social problems in a more scalable way than individual social entrepreneurs.

This Special Issue also features two in-depth case studies of 'heroic' social entrepreneurs and their multiaward winning creations. Yet, both case studies move beyond the laudable and inspiring actions of visionary social entrepreneurs by demonstrating and analysing how the organisations they built grew, how they were scaled up in size, and ultimately, how they became sustainable.

In their 'In Pursuit of Dignity \& Social Justice: Changing Lives Through $100 \%$ Inclusion. How Gram Vikas fosters sustainable rural development' Nicola M. Pless and Jenny Appel investigate an innovative social entrepreneurial approach to sustainable rural development pioneered by Gram Vikas through its 'Water and Sanitation Program'. Gram Vikas, founded by former student leader Joe Madiath, is one of India's most prominent social enterprises. The authors explore how Gram Vikas develops sanitation programs in India's poorest regions and its key innovation of $100 \%$ inclusion and the process of creating democratic, self-governing management systems. Pless and Appel demonstrate how Gram Vikas contributes to the United Nations Millennium Goals of improving health, empowering women, breaking the vicious circle of poverty, and ultimately, realising the vision of 'an equitable and sustainable society where people live in peace and dignity'. The authors conclude by discussing the management challenges that the organisation faces in the area of finance, personnel management and the scaling up its efforts.

A country known for its dubious governments and longstanding struggle with corruption may not be the obvious choice for a socio-economic revolution that is expected to play an important role in the elimination of global poverty. However, Paraguay, an 'island without shores', as the writer Augusto Roa Bastos once described it, is home to one of the world's most innovative social enterprises - the Fundación Paraguaya. In their article, 'Social Entrepreneurs as Responsible Leaders: 'Fundación Paraguaya' and the Case of Martín Burt' Thomas Maak and Nicolas Stoetter discuss the responsible leadership of Martín Burt and analyse the organisation's pioneering approach to solving social problems under difficult socioeconomic circumstances, and its increasingly global effort to eradicate poverty. While the achievements and success of Fundación Paraguaya are the result of a team effort, its remarkable development can be largely attributed to the vision, inspiration and guidance of its founder and chief executive Martín Burt. The organisation's vision is to be 'a 
leading social enterprise that develops innovative solutions to poverty and unemployment and actively shares its experience around the world'. The last part underscores the social purpose of the venture, which is not to sell its model to maximise profits, but to promote ideas to maximise social impact. In so doing, social value is created within the organisation and its social network. Its business model is not about gaining a larger share of the pie, but about making the pie larger-in a sustainable and financially selfsufficient manner. It is no surprise that Fundación Paraguaya is the first and longest-running non-governmental organisation in Paraguay.

\section{References}

Bornstein, D. (2004). How to Change the World: Social Entrepreneurs and the Power of New Ideas. New York: Oxford University Press.
Dacin, M. T., Dacin, P. A., \& Tracey, P. (2011). Social entrepreneurship: A critique and future directions. Organization Science, 22(5), 1203-1213.

Koe Hwee Nga, J., \& Shamuganathan, G. (2010). The influence of personality traits and demographic factors on social entrepreneurship start up intentions. Journal of Business Ethics, 95, 259-282.

Mair, J., \& Marti, I. (2006). Entrepreneurship in and around institutional voids: A case study from Bangladesh. Journal of World Business, 41, 36-44.

Murphy, P., \& Coombes, S. (2009). A model of social entrepreneurial discovery. Journal of Business Ethics, 87, 325-336.

Short, J. C., Moss, T. W., \& Lumpkin, G. T. (2009). Research in social entrepreneurship: Past contributions and future opportunities. Strategic Entrepreneurship Journal, 3, 161-194.

Sud, M., VanSandt, C. V., \& Baugous, A. M. (2009). Social entrepreneurship: The role of institutions. Journal of Business Ethics, 85, 201-216.

VanSandt, C. V., Sud, M., \& Marme, C. (2009). Enabling the original intent: Catalysts for social entrepreneurship. Journal of Business Ethics, 90, 419-428. 